\title{
Experimental micromechanical characterisation of wood cell walls
}

\author{
Michaela Eder • Olivier Arnould • \\ John W. C. Dunlop • Joanna Hornatowska • \\ Lennart Salmén
}

Received: 4 July 2012/Published online: 27 October 2012

(C) Springer-Verlag Berlin Heidelberg 2012

\begin{abstract}
The properties of wood and wood-based materials are strongly dependent on the properties of the fibres, that is, the cell wall properties. It is thus highly important to be able to mechanically characterise cell walls in order to understand structure-property relationships. This article gives a brief overview of the state of the art in experimental techniques to characterise the mechanical properties of wood at both the level of the single cell and that of the cell wall. Challenges, opportunities, drawbacks and limitations of single fibre tensile tests and nanoindentation are discussed with respect to the wood material properties.
\end{abstract}

\section{Introduction and background}

An understanding of the mechanical response of wood is essential to understand (and predict) the stability of living trees or equally important for the behaviour of wood when it is used for construction purposes. In addition to these fundamental requirements, wood micromechanical data are important input parameters in applications such as the manufacture of fibre-based products like cardboard and paper, as well as helping this resource to be used in a targeted, efficient, economic and sustainable way in, for example, building construction.

\footnotetext{
M. Eder $(\bowtie) \cdot$ J. W. C. Dunlop

Max-Planck-Institute of Colloids and Interfaces, Wissenschaftspark Golm, 14424 Potsdam, Germany

e-mail: michaela.eder@mpikg.mpg.de

O. Arnould

Laboratoire de Mécanique et Génie Civil (LMGC), CNRS UMR5508,

Université Montpellier 2, Place E. Bataillon, cc 048, 34095 Montpellier Cedex 5, France

J. Hornatowska · L. Salmén

Innventia, Box 5604, 11486 Stockholm, Sweden
} 
The biological material wood is formed under hydrated conditions by the living tree, mainly to ensure water transport and mechanical stability. It is a hierarchically structured material with levels (length scales) that might be termed (Speck et al. 1996) as the integral (tree as a structure), macroscopic (annual rings), microscopic (cellular), ultrastructural (cell wall) and biochemical levels (polymers). Each of these levels shows a characteristic architecture, that is, dependent both on the tree species and the location within the tree. In addition to this, environmental conditions are also reflected in the material architecture at particular length scales, like the formation of reaction wood which generates active stresses that allow the tree to direct organs in particular directions (Wardrop 1965; Scurfield 1973; Archer 1986; Bonser and Ennos 1998; Yamamoto et al. 2002; Moulia et al. 2006; Burgert et al. 2007; Alméras and Fournier 2009). All these dependencies of properties on wood structure are equally important from both a biological and a technological perspective. However, if the point of view is changed and wood is evaluated as a material for applications, the process of wood drying comes immediately into focus. Changes in moisture content lead to considerable changes in material properties at all hierarchical levels (Barkas 1939; Kollmann 1951; Niemz 1993; Eder 2007; Olsson et al. 2007). This property has led to the development of a variety of techniques (controlled drying processes, laminates) that make wood products appropriate for more and more applications. This is still an ongoing process where an improved understanding of the micromechanics of wood is highly important.

It is well known that parameters such as density, fibre orientation and moisture content strongly influence the mechanical performance of wood at larger length scales. However, studies at the ultrastructural level, in particular on the orientation of cellulose microfibrils, revealed its considerable role on wood material properties, for example, mechanical performance and dimensional (in)stability (Barber and Meylan 1964; Cave and Hutt 1969; Page et al. 1972, 1977; Dinwoodie 1975; Reiterer et al. 1999), and highlighted the importance of exploring wood on small length scales. Furthermore, such approaches allow the measurement of local structural and mechanical parameters that in turn control material performance at higher levels.

The following prominent examples should briefly illustrate research areas that might profit from experimental micromechanical characterisation of wood:

- wood fibre-based industries (pulp and paper, fibreboard, wood-plastic composites)

- modelling wood mechanics - from ultra- to macro-structure

- characterisation of modifications altering cell wall properties and on which hierarchical level they act

- resistance against microbial degradation (durability), dimensional stability

- biology: to understand cell wall formation and cell wall mechanics with respect to the needs of living tree-properties, structure, function.

This article gives an overview of two frequently used methods that allow experimental characterisation of mechanical properties at the cell (fibre) and the cell 
wall: single fibre microtensile tests and nanoindentation. Special emphasis will be laid on their applicability to wood. Collected data from literature are presented and will be discussed and compared with respect to the limitations of the two different methods.

\section{Micromechanical tensile tests, esp. single fibre tests}

A. A. Griffith, the famous English engineer and pioneer in fracture mechanics, described in his publication "The phenomena of rupture and flow in solids" (Griffith 1921) a method to measure single glass fibre strength: “... one end of a fibre was attached to a stout wire hanging on one arm of a balance, and the other end to a fixed point, the medium of attachment being sealing wax. A slight tension was applied while the wax was still soft, in order to eliminate bending of the fibre at the points of attachment. The other arm of the balance carried a beaker into which water was introduced from a pipette or burette. The weight of water necessary to break the fibre was observed and the diameter of the latter at the fracture was found by means of a high-power measuring microscope. Hence the tensile strength was obtained ...". The invention of strain gages by E. E. Simmons and A. C. Ruge in 1938 facilitated force measurements considerably allowing the measurement of both smaller and larger forces. Another 20 years passed until the first tensile tests were performed on wood fibres with typical lengths ranging from 0.5 to $3 \mathrm{~mm}$ and diameters of $15-40 \mu \mathrm{m}$.

The first tensile tests on single wood fibres

In 1959, Jayne published his paper "Mechanical properties of wood fibres", which gives the first experimental procedure describing single wood fibre testing. He used a tensile testing machine, where forces were recorded by a load cell based on strain gages. Strains were calculated on the basis of cross-head displacement. It turned out that most of the experimental difficulties were related to the clamping of the fibres (which is still the case nowadays). Methods used in the textile industry were not practicable because of the shortness of wood fibres. After several trials with wires, glues, etc., he managed to clamp the fibres by using abrasive papers.

Since then, many different procedures for testing have been developed, see, for example, the detailed review of the early literature by Ehrnrooth and Kolseth (1984). In the following section, some key developments are briefly discussed that now serve as a basis for current experimental mechanical characterisation. Page et al. (1971) developed a frame construction where the ends of pulp fibres were glued to glass tabs. A stiff card held the glass tabs together, and it was mounted on the testing machine jaws. The card was cut before the start of the test. This mounting method has been used in many investigations of single fibres, where different materials such as metal tubes or paper have been used as tabs for gripping in the tensile testing jaws. A similar principle was also applied by Burgert et al. (2002). Later, Burgert et al. (2003) enhanced the method by designing a 200- $\mu$ mthick foliar frame which allowed for a certain alignment of the fibre during the test. 
Another method, which allows alignment of single fibres during tensile tests, is the clamping method described by Kersevage (1973) and Mott et al. (1995). The method is based on the application of epoxy droplets to the fibre ends. The epoxy droplets are assumed to minimise stress concentrations close to the gripping of the fibre ends. Mott et al. (1995) and Groom et al. (2002) further modified and improved Kersavage's method, by changing the mounting system. This resulted in a testing procedure where the number of tested fibres could be increased significantly. The new mounting method was more favourable because it should allow the fibres to be aligned keeping them straight during loading. Recently, Yu et al. (2011b) presented another method to grip short plant fibres with epoxy glue droplets at the fibre ends.

\section{Strain measurements}

The easiest way of determining the average longitudinal strain is to calculate it on the basis of the cross-head displacement (Jayne 1959). This calculation needs to be corrected in order to take, at least, the tensile machine, frame card and the clamping (e.g. glue droplets) compliance into account. To avoid this, simultaneous longitudinal strain measurement close to the fibre by video extensometry has been developed (Burgert et al. 2003). Moreover, strain fields for the surface of the fibre can be obtained by using digital image correlation in for instance an ESEM (Mott et al. 1996; Bergander and Salmén 2000a).

Cross-sectional areas and stress calculation

To obtain stress-strain curves from force-displacement data, the cross-sectional area of the fibres needs to be determined. In recent investigations, the crosssectional area along the fibre was measured by confocal laser scanning microscopy (CLSM) (Wild et al. 1999; Groom et al. 2002; Sedighi-Gilani and Navi 2006; Hornatowska 2009; Yu et al. 2011b) or by environmental scanning electron microscopy ESEM (Burgert et al. 2003). If the fibre walls are stable enough and not collapsed, stresses can be determined both for whole cell cross-sections (cell wall and lumen) and for cell wall cross-sections by dividing the measured force by the measured area.

\section{Stress-strain curves}

The calculation of the stress together with the deformation allows a stress-strain curve to be plotted (a schematic of such a curve is given in Fig. 1a). From such a curve, a variety of representative mechanical parameters can be derived. The tensile stiffness (otherwise known as the elastic or Young's modulus E) is determined as the slope of the lower, linear "elastic" region of the curve. This region is characteristic of a reversible response of the material, in terms of stress (or strain) to applied strains (or stresses). The yield point is the point at which the stress-strain curve becomes nonlinear, and more accurately speaking, occurs when deformation becomes irreversible and the material starts to flow. The shape of the stress-strain curve is strongly structure dependent. The area underneath this curve corresponds to the 

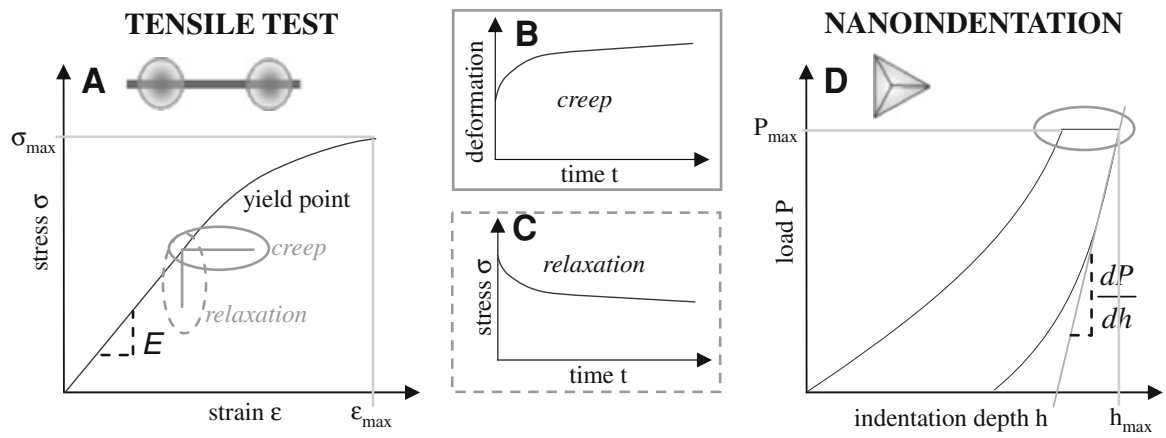

Fig. 1 Schematic stress-strain and loading-unloading curves obtained during tensile tests (a) and nanoindentation experiments (d). b, $\mathbf{c}$ Characteristic creep and relaxation curves

energy of deformation and is often used as a proxy for toughness. The maximum stress achieved before the fibre breaks is termed here the ultimate tensile stress (UTS).

\section{Combined methods}

Combining microtensile tests with other methods allow structural changes at different length scales to be related to the material response at defined stress and strain levels. Failure mechanisms of individual fibres have been observed and studied by ESEM (Mott et al. 1995; Seisto et al. 1998; Eder et al. 2008a). Polarised light microscopy allows the visualisation of areas with deviant cellulose fibril alignment with respect to the main cellulose orientation allowing the response of dislocations or nodes (defects) to straining to be studied (Thygesen et al. 2007; Eder et al. 2008b). When changes in the crystal lattice of cellulose or in microfibril angles (MFA) should be studied in more detail, in situ X-ray experiments are a powerful method (Köhler and Spatz 2002; Keckes et al. 2003; Kamiyama et al. 2005; Kolln et al. 2005; Peura et al. 2005, 2006, 2007; Zabler et al. 2010; Montero et al. 2012). Spectroscopic methods (see review Fackler and Thygesen, this issue) combined with mechanical loading allow one to follow changes at the molecular level caused by straining (e.g. Eichhorn et al. 2001; Hinterstoisser et al. 2001; Gierlinger et al. 2006).

Variations on single fibre mechanical tests

As with macroscopic mechanical testing, the loading procedure can be varied allowing for a wide range of testing conditions on the single fibre or fibre walls. For example, Wild et al. (1999) constructed a tester, allowing cyclic axial and even transverse loading to be applied to individual fibres at varying humidity and temperature. Torsional properties of wood fibres and the effects of environment have been extensively studied by Kolseth (1983) and by Kolseth and Ehrnrooth (1986). The low throughput of single fibre testing can be improved by testing multiple fibres concurrently in the Single Fibre Fragmentation (SFF) test (Ljungqvist 2004) giving a breaking strain distribution from a number of fibres. 
Other variations of fibre testing include the determination of the bending or apparent modulus of elasticity by testing wood fibre cantilevers prepared by focussed ion beam milling tested in bending by AFM (Orso et al. 2006) as well as compression testing using micropillars to determine the compressive strength of the $\mathrm{S}_{2}$ layer (Adusumalli et al. 2010; Zhang et al. 2010). Measurements of transverse fibre wall elastic properties have also been demonstrated using radial double-wall cut strips strained in an ESEM tensile stage (Bergander and Salmén 2000a, b).

\section{Nanoindentation}

Nanoindentation (NI) otherwise known as instrumented or depth-sensing indentation (Oliver and Pharr 1992, 2010; Fisher-Cripps 2011) is nowadays a wellestablished technique to characterise mechanical properties of materials at very small length scales. In comparison with tensile tests, nanoindentation on wood is a rather "young" experimental technique. For the first time it was applied by Wimmer et al. (1997) on the cross-sectional plane of fibre walls.

The measuring principle is essentially an extension of the simple hardness test that has been used in a variety of different forms for over 250 years. In hardness testing, the resistance of a material against localised and permanent deformation is measured by pushing a stiff indenter with a given geometry (e.g. cone, sphere, pyramid, flat punch) into the surface with a given fixed load and then measuring the area of the resultant indent. The hardness is then defined as the ratio of a given maximum load $\mathrm{P}$ and the projected residual indent area $A_{r}$ (e.g. Fisher-Cripps 2011). The smaller the indent area for a given load, the more resistant and thus the harder the material is. On macroscopic wood samples, hardness is usually measured on the tangential plane with a spherical or cylindrical indenter (e.g. Janka, or Brinell, and Monnin hardness test) (Doyle and Walker 1985). The Vicker's microhardness test is a scaled down version of the hardness test and allows experiments to be performed on smaller length scales and thus lower hierarchical levels. The hardness gives information about the resistance of a material to permanent deformation and is somewhat related to the yield stress in uniaxial tensile compression testing especially for metals (Tabor 1951, 1996).

Nanoindentation follows roughly the same procedure as hardness testing; however, the load and the displacement of the indenter are monitored (and controlled) with high accuracy during the experiment. This has the major advantage that, in addition to being able to get more accurate and faster hardness values, it is also possible to extract features from an indentation curve like, among others, a parameter related to the elastic properties of the material (Fisher-Cripps 2011). A typical loading-unloading curve of a nanoindentation experiment is given in Fig. 1d in which the applied force $P$ is plotted against the penetration depth $h$ of the indenter into the sample. From this curve, it is possible to compute directly the classical hardness without measuring the residual indent area, if the indenter shape is known. The residual depth $h_{\mathrm{r}}$ is converted to the residual indent area $A_{\mathrm{r}}$ through the socalled "shape function" (Oliver and Pharr 2010; Fisher-Cripps 2011). The most 
frequently used shape is the so-called Berkovich indenter which is a 3-sided pyramid with a face angle $\theta=65.27^{\circ}$, having the following shape function:

$$
A=3 \sqrt{3} h^{2} \tan ^{2} \theta=24.494 h^{2} .
$$

In practice, the real shape of an indenter is taken into account by calibration on fused silica.

\section{Indentation modulus}

During an experiment, the material under the tip deforms both plastically and elastically during loading. Upon unloading, however, only the elastic part relaxes (at least at the start of the unloading curve), which allows the calculation of an effective local stiffness of the material known as the indentation or reduced modulus, $E_{r}$. This stiffness is determined from the initial (elastic) unloading slope $\mathrm{d} P / \mathrm{d} h$ (Oliver and Pharr 1992) (Fig. 1d):

$$
E_{r}=\left.\frac{1}{\beta \sqrt{A_{\max }}} \frac{\mathrm{d} P}{\mathrm{~d} h}\right|_{h_{\max }},
$$

where $A_{\max }$ is the projected contact area under load between the indenter and the material (estimated using the shape function and the contact depth area) and $\beta$ a factor depending on the indenter shape, for example, 1.23-1.24 for a Berkovich indenter (Oliver and Pharr 2004; Jakes et al. 2008; Fisher-Cripps 2011). It is possible to record this stiffness all along the loading curve using a Continuous Stiffness Measurement (CSM) less used in wood science (Tze et al. 2007).

For elastically isotropic materials, the indentation modulus can be related to the sample elastic modulus $E_{\mathrm{s}}$ if the Poisson's ratio $v_{s}$ of the tested material as well as the elastic properties of the indenter material, $E_{i}$ and $v_{i}$, are known through the following relation:

$$
\frac{1}{E_{r}}=\frac{1-v_{i}^{2}}{E_{i}}+\frac{1-v_{s}^{2}}{E_{\mathrm{s}}} .
$$

Of course wood and most other materials (including many metals, particularly at small length scales) are anisotropic. Due to the complex deformation field under the indenter tip, the indentation modulus of anisotropic materials therefore can only be viewed as being a sort-of "geometric average" of the elastic tensor (Vlassak et al. 2003; Jäger et al. 2011a). A correct estimation of all (or some) anisotropic material elastic parameters requires more information about the material eigen directions such as its microfibril angle (Gindl and Schöberl 2004) combined with further experiments using different load, indenter shapes and orientations (Jäger et al. 2011b).

\section{Viscoelastic measurements}

As the rate of loading is controlled during nanoindentation (see, e.g., Fisher-Cripps 2011), optional holding times (Fig. 1d, grey circle), usually greater than $5 \mathrm{~s}$ for the $\mathrm{S}_{2}$-layer, can be introduced prior to unloading in order to minimise viscoelastic 
effects during unloading (Cheng and Cheng 2004). These segments can also be interpreted to measure creep behaviour. The horizontal line in the grey circle in Fig. 1a indicates a creep experiment with a tensile tester. In both cases, the force is held constant for a certain period and the resulting deformation is recorded (Fig. 1b). The grey, dashed circle indicates relaxation experiments where the deformation is kept constant and the decreasing force is recorded (Fig. 1c). In principle, a similar procedure can be used to measure relaxation during indentation. Other less used viscoelastic measurement mode in wood science is the nano-DMA (Gershon et al. 2010).

For other mechanical properties that can be obtained by analysing the loading/ unloading curve, such as strain-hardening index, fracture toughness, yield strength and residual stress under specific conditions, as well as experimental precautions or required corrections, such as indenter apex shape, device compliance, etc. see Fisher-Cripps (2011).

\section{Going down to the nanometre scale}

To study other cell wall layers than the $S_{2}$ or cell corners and to reach the ultrastructural level, it is necessary to reduce the measurement scale. Atomic Force Microscopy (AFM) allows measurements similar to nanoindentation but at a lower scale using force-displacement curves, and sometimes dedicated tips, as demonstrated on polymers (Tomasetti et al. 1998). Such a technique has been used for measuring the elastic modulus of cellulose fibrils in bending (Cheng and Wang 2008). A large number of advanced AFM techniques are currently in development for measuring mechanical properties, see, for example, Bhushan and Fuchs (2009); however, only a few have yet been applied to wood cell mechanics. To our best knowledge, mainly the so-called "Resonant Contact-AFM" (RC-AFM) has been used for estimating elastic properties in the wood cell wall (Clair et al. 2003; Bytebier et al. 2009; Nair et al. 2010). Some new techniques, that operate in the intermediate scale between nanoindentation and AFM, are currently being developed and show promise for wood micromechanics like the "Scanning Microdeformation Microscope" (SMM) that is similar to the RC-AFM but at a higher scale (Le Rouzic et al. 2012) and the ultra-nano hardness tester (UNHT from CSM instruments).

\section{Sample preparation: methodological limitations}

The following section briefly discusses the respective requirements for sample preparation for single fibre tensile tests and nanoindentation.

Single fibre tests demand the isolation of tracheids, fibre tracheids or libriform fibres out of a particular wood tissue. Depending on the particular research question, chemical or mechanical isolation can be applied. Chemical isolation procedures are the method of choice when particular isolation protocols should be followed to simulate industrial processes or to remove certain cell wall components. When the fibres should be retained in their natural condition without altering cell wall 
composition and architecture, a mechanical isolation technique performed with fine tweezers under a light microscope is the appropriate method (Burgert et al. 2002).

Both isolation techniques allow the fibres to be either kept wet or dried to a defined state. Humidity changes in the environment cause an immediate response in the hygroscopic cell wall, which results in many cases in a considerable twisting of the fibre (Kolseth 1983; Kolseth and Ehrnrooth 1986). This makes it tricky to mount a fibre with defined moisture content onto a testing device. In practice, never-dried, green fibres are put into glycerine to prevent them from drying. Fibres, where a drying step is not problematic, are typically dried under glass slides and afterwards glued in the dry state and subjected to the desired climate before and during the tensile test.

Until now no tensile tester has been developed which allows the accurate determination of tensile properties of fibres shorter than $0.5-0.7 \mathrm{~mm}$. There are no such limitations with nanoindentation for an isotropic material. However, it is commonly admitted that the radius of the elastically affected volume around the tip is about 3 times the residual indent radius. Wimmer et al. (1997) found that stiffness results depend on the location of the indent in the cell wall as the thickness of the $\mathrm{S}_{2}$ layer in wood cell walls is $\sim 0.3-4 \mu \mathrm{m}$, which is of a similar scale to this volume. Thus, a correct choice of loading-unloading conditions needs to be applied. In a more recent publication, Jakes et al. (2009a) studied the effect of the location of an indent close to an edge, which can be both a free edge and a heterophase interface, and suggested the application of a factor correcting for structural compliance. The use of embedding materials rigidifies the wood sample and helps to reduce edge effects. Besides this, the required flat sample surfaces are easier to prepare on embedded wood samples, either by ultramicrotoming or by polishing. The interested reader is referred to the following publications that contain discussions about the penetration of embedding resin and a variety of preparation procedures (Jayme and Fengel 1962; Fengel 1967; Wimmer and Lucas 1997; Wimmer et al. 1997; Hepworth et al. 2000; Zimmermann et al. 2006; Kamke and Lee 2007; Tze et al. 2007; Konnerth et al. 2008).

The main limiting factor in nanoindentation experiments, besides the minimum indent size, is clearly the lack of knowledge regarding the effective wood moisture content in the elastically tested volume, and it is all the more true for embedding samples. Even when resin penetration into the cell wall can be completely excluded, swelling or shrinkage due to changes in relative humidity might be restricted or increased in both directions by the embedding material that could cause stresses in the cell walls. This might lead to alterations of mechanical properties due to the development of microcracks.

\section{Examples for micromechanical properties}

Elastic cell wall properties

\section{Single fibre testing}

In Fig. 2, tensile test modulus data are plotted against the MFA that is known to be a crucial structural parameter on the cell wall level with a strong influence on the 
mechanical performance (Cave and Hutt 1969; Page et al. 1977; Reiterer et al. 1999). For single fibre measurements, each data point represents a mean value of several tests, collected both from more recent literature and partly unpublished data (Mott et al. 2002; Burgert et al. 2004; Keunecke et al. 2008; Eder et al. 2009; Wang et al. 2011). Rectangles represent modulus values of chemically isolated fibres, tested under dry conditions. Triangles show modulus values of mechanically isolated fibres (unfilled triangles — wet condition, filled triangles - dry condition). These values are lower than earlier reported ones from Page et al. (1977) a fact probably related to the fact that these fibres were pulp fibres with an eventually higher cellulose content than the corresponding wood fibres here shown. Nevertheless, relative comparisons show the same trend of decreasing tensile moduli with increasing microfibril angle.

The effect of moisture on mechanical properties, the difference in modulus between wet (unfilled triangles) and dry (filled triangles and rectangles) fibres being tested in tension, is much larger for fibres with high cellulose microfibril angles (zoomed-in area in Fig. 2). Kersevage (1973) reported a drop in longitudinal stiffness of $\sim 10 \%$ for adult single fibres (typically low microfibril angles) due to increasing moisture content. For compression wood fibres, which are known to have very high microfibril angles, a stiffness reduction up to $50 \%$ has been reported (Sedighi-Gilani and Navi 2006; previously unpublished data in Fig. 2). This fits well with theoretical calculations of the relative stiffness reduction due to moistureinduced softening of hemicelluloses, based on fibre wall lamination models (Salmén 2004). Of course, the chemical composition of a compression wood fibre is different from that of an adult wood fibre but Kolseth and Ehrnrooth (1986) showed that the content of hemicelluloses and lignin in the fibres only marginally affect stiffness reduction caused by an increase in moisture content. Hence, the very low stiffness reduction with increasing moisture in fibres with low microfibril angles can be

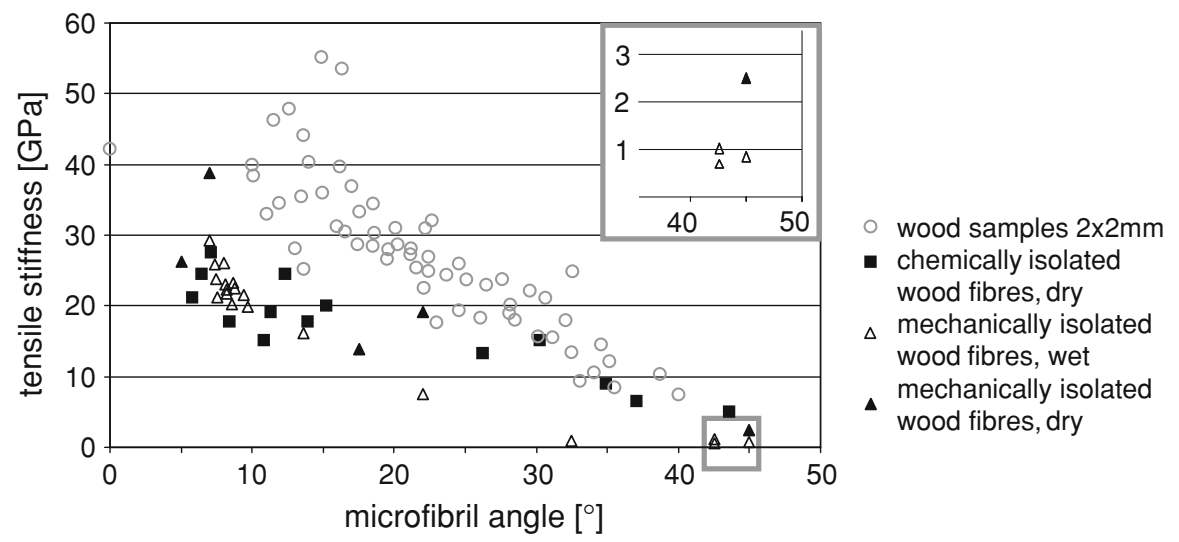

Fig. 2 Tensile test moduli data plotted against microfibril angles. Rectangles, filled and unfilled triangles display mean values from tensile tests on single fibres (Mott et al. 2002; Burgert et al. 2004; Keunecke et al. 2008; Eder et al. 2009; Wang et al. 2011). Grey circles show single measurements performed on $2 \times 2 \mathrm{~mm}^{2}$ wood samples (Cave and Hutt 1969). Inset shows detail of the stiffnesses of high microfibril samples 
explained by the properties of cellulose microfibrils in the longitudinal direction that are almost unaffected by the water content, while at high MFA, the reinforcing effect is lost and fibre properties are more dependent on the matrix properties which are strongly dependent on hydration (Salmén 2004). With increasing cellulose microfibril angle, the shear stresses in the matrix reach a maximum at an angle of $45^{\circ}$ and therefore lower the tensile stiffness disproportionately for wet fibres with high microfibril angles compared to those with lower microfibril angles. So far no comprehensive experimental data set on tensile stiffness as a function of moisture content and microfibril angle exists. In contrast to the moisture conditions, the influence of the isolation procedure, chemically (rectangles in Fig. 2a) or mechanically (filled triangles), onto cell wall stiffness is rather small, see also (Burgert et al. 2005).

In comparison with the properties of isolated fibres, the grey circles in Fig. 2 show data of tensile tests performed on clear wood specimens with a cross-section of $\sim 2 \times 2 \mathrm{~mm}^{2}$ (Cave and Hutt 1969). Stresses were calculated on the cell wall area in a given cross-section. In comparison with the single fibre data tensile moduli reach higher values. This example nicely illustrates the ingenuity of hierarchical structuring: within the tissue, fibres are restricted from twisting or buckling by neighbouring cells. Twisting and buckling are deformation modes when helically wound tubes are strained in tension (Pagano et al. 1968). A wood fibre with its dominant $\mathrm{S}_{2}$ layer can be considered being such a tube. The different behaviour due to the different testing conditions was illustrated by Salmén and de Ruvo (1985) in a model describing the deformation behaviour of a single fibre when restrained and free to twist under tension. This model describes well the differences here shown between the testing of wood (restricted twisting) and single fibres (free twisting). Additionally fibre cross-sections may vary along the fibre length and contain local anatomical "defects" (e.g. fibre ends, pits) (Neagu et al. 2006; Sedighi-Gilani et al. 2005,2006 ), which lead to stress/strain concentrations. This may give rise to a smaller apparent elastic modulus if it is not taken into account; the tissue compensates to a large amount for this. Finally, damage and kinking can occur during the isolation and subsequent sample preparation process also adds to the scatter in the data.

\section{Nanoindentation}

In Fig. 3, reduced modulus values obtained by the compilation data of nanoindentation on resin embedded wood samples in dry condition are plotted against the MFA. Each data point corresponds to the mean values reported from the literature for non-modified wood samples; with reduced modulus back calculated when necessary. Filled rectangles correspond to softwood samples (Wimmer and Lucas 1997; Gindl et al. 2004; Tze et al. 2007; Konnerth et al. 2009; Brandt et al. 2010; Jäger et al. 2011b), whereas unfilled triangles correspond to hardwood sample (Wu et al. 2009; De Borst et al. 2012). In contrast to Fig. 2 where the $x$-axis ends at $50^{\circ}$, which is a natural limitation (microfibril angles higher than $50^{\circ}$ are typically not found in wood fibres), the $x$-axis of the diagram in Fig. 3 is extended to $90^{\circ}$ because here samples can be rotated or tilted which allows indenting transversely to the 
cellulose fibril alignment (Brandt et al. 2010; Jäger et al. 2011b). Again, absolute values of stiffness obtained by nanoindentation in the $S_{2}$-layer are much lower than what is normally expected for the longitudinal modulus (Fig. 2). In the case of nanoindentation, this is mainly due to the complex loading under the indenter that yields a reduced modulus that depends not only on the longitudinal modulus but also on the (lower) shear and transverse moduli (Gindl and Schöberl 2004; Jäger et al. 2011a). Anisotropic models for the reduced modulus obtained by nanoindentation have been successfully applied in the case of the softwood $\mathrm{S}_{2}$-layer by Jäger et al. (2011a). Such models can be used for a reverse identification of some of the elastic moduli of the $S_{2}$-wall, for details see review paper by Gamstedt et al. (this issue) and Jäger et al. (2011b).

Nanoindentation experiments also demonstrate that stiffness decreases with increasing cellulose microfibril angle. However, stiffness changes due to changes in microfibril angle are lower for nanoindentation compared to tensile tests, in particular for microfibril angles below $20^{\circ}$ and above $60^{\circ}$. The rather strong sensitivity of nanoindentation tests to changes in microfibril angle in the range of $20^{\circ}-60^{\circ}$ implies that samples need to be properly aligned with respect to the actual microfibril angle in the indentation volume (Konnerth et al. 2009; Jäger et al. 2011b). The high data scattering in Fig. 3 refers to sensitivity of nanoindentation measurements to the wall composition and particularly to the matrix composition as this Figure contains data for softwood, hardwood, juvenile, normal, opposite and compression wood as well as early, transition and late wood. This measurement technique provides thus a powerful tool to, for example, study the effect of wood modification on cell wall properties (Gindl and Gupta 2002; Zickler et al. 2006; Xing et al. 2008; Stanzl-Tschegg et al. 2009; Brandt et al. 2010; Konnerth et al. 2010; Yin et al. 2011) or the lignification of the wood cell wall during maturation (Gindl et al. 2002).

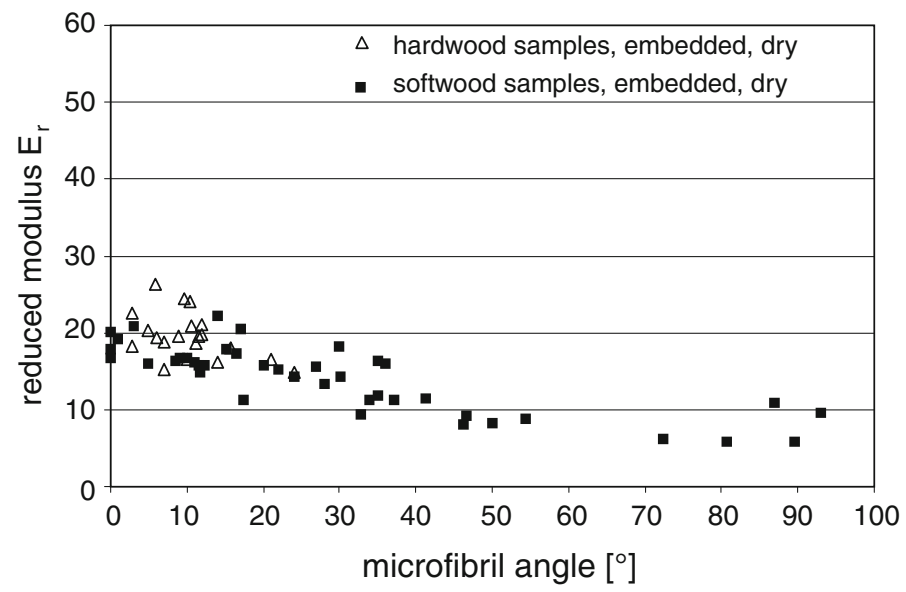

Fig. 3 Reduced moduli data (mean values) plotted against microfibril angles. Rectangles show measurements on softwood (Wimmer and Lucas 1997; Gindl et al. 2004; Tze et al. 2007; Konnerth et al. 2009; Brandt et al. 2010; Jäger et al. 2011b), triangles show measurements on hardwoods (Wu et al. 2009; De Borst et al. 2012) 
Despite targeted modifications, it is well known that wood cell wall properties are strongly dependent on moisture conditions. As mentioned in the sample preparation section, humidity-controlled nanoindentation experiments are difficult to perform, particularly as the moisture content of the tested layer is unknown. However, (Yu et al. 2011a) showed a reduction of $\sim 17 \%$ in the reduced modulus when the macroscopic moisture content went from 3.5 to $13 \%$.

\section{Strength}

\section{UTS: ultimate tensile stress}

As mentioned in the introduction UTS is a measure that can easily be determined from stress-strain curves of single fibre tensile tests. One needs to be aware that an accurate determination is difficult to achieve because the cross-section is not constant along the fibre length as well as that pits and other structural inhomogeneities can be found. Still a relative comparison of data is meaningful, for example, between different fibre types (Page and El-Hosseiny 1983; Mott et al. 2002; Burgert et al. 2004), environmental conditions (Kersevage 1973; Ehrnrooth and Kolseth 1984), different fibre geometry (Eder et al. 2008a, b) isolation procedures (Burgert et al. 2005) and modifications (Goswami et al. 2008). The fact that fibres tend to break at their weakest point makes this method highly suitable to study fibre defects, for example, naturally caused, introduced by processing or isolation procedure (Page et al. 1972; Kim et al. 1975; Page and El-Hosseiny 1976; Eder et al. 2008a, b). These different factors might also be the reason why the influence of moisture on UTS is not very clear from literature data (Hartler et al. 1963; Kallmes and Perez 1966; Leopold and Thorpe 1968; Kersevage 1973).

\section{Hardness}

Compilation of hardness data obtained by nanoindentation in the $\mathrm{S}_{2}$-layer of different types of cells from softwoods mainly shows that there is no obvious tendency between hardness and MFA (Wimmer et al. 1997; Gindl et al. 2004; Tze et al. 2007; Konnerth et al. 2009; Yin et al. 2011). Results are highly scattered in the range 0.35-0.55 GPa. Moreover, difference in hardness values between the cell corner middle lamella and the $S_{2}$ wall is neither significant (Wimmer and Lucas 1997; Jakes et al. 2008). The hardness increases with lignin content in developing cells (Gindl et al. 2002). In hardwoods, a similar order of magnitude has been reported (StanzlTschegg et al. 2009) with no significant difference in hardness between 10 hardwood species with different MFA (Wu et al. 2009). Following the idea of Gindl and Schöberl (2004) and Gindl et al. (2004), hardness seems mainly dependant on the cell wall matrix properties. Later results on hygrothermally or chemically modified wood strengthen this assumption. Stanzl-Tschegg et al. (2009) show that a strong thermal treatment $\left(220^{\circ} \mathrm{C}\right)$ weakly affects the reduced modulus, whereas it significantly increases hardness of a beech $\mathrm{S}_{2}$-layer. Steam (hygrothermal) treatment leads to a significant reduction in hardness especially for temperatures higher than $140{ }^{\circ} \mathrm{C}$ (Yin et al. 2011). Yu et al. (2011a) found that hardness is more sensitive than the reduced 
modulus with changes in moisture content. All these results show that the cell wall matrix behaviour, and its modification, is prevailing on hardness. This could be explained by the complex loading under the indenter with a strong plastic deformation that probably relies on microfibrils organisation and damage (by bending, buckling, kinking, etc.) and high strain in the matrix. Brandt et al. (2010) measured hardness perpendicularly to the fibre axis, for example, in the radial and tangential direction of the $S_{2}$-layer, and obtained values around two times smaller than in the cross-section of the fibre. One can imagine that the indenter penetration in the cell wall, and interaction with the microfibrils network, is different for a radial or tangential loading. To the authors' best knowledge, no detailed modelling of the plastic deformation process of wood under the indenter tip has been done. In metals, a significant amount of work has been done in this direction (e.g. Tabor 1996); however, this relies on the detailed knowledge of the elementary processes of plastic deformation, which is missing for wood.

Time-dependent behaviour, mechano-sorptive creep

Even though they are difficult to perform, creep experiments are possible both with nanoindentation (Jakes et al. 2009b; Stanzl-Tschegg et al. 2009) and with single fibre tensile tests (Ehrnrooth and Kolseth 1984). When the humidity is changed during a creep experiment on wood, the creep rate is increased. The impact of this phenomenon is considerable, for example, it is a major cause of why cardboard boxes collapse during shipping. In contrast to "pure" creep experiments, the study of mechano-sorptive creep of the cell wall is currently restricted to single fibres (Navi et al. 2006; Olsson et al. 2007; Dong et al. 2010). The decisive factor is the fast response to changing humidities of a very small, unembedded sample. Interestingly, it was shown that the mechano-sorptive creep seems to be diminishing with increasing MFA and may be non-existing at a MFA of $45^{\circ}$ (Dong et al. 2010).

\section{Conclusion and perspectives}

The experimental techniques of single fibre tensile test and nanoindentation allow for an in depth mechanical characterisation of wood cell walls. Both techniques have limitations that are strongly related to the structure and composition of the cellular wood material. The main limiting factor for single fibre tests is currently that a certain fibre length is required, which excludes short fibres (mainly hardwood and juvenile) to be tested and the fact that isolated cell walls cannot yet be tested in their transverse directions. Sample preparation with the aid of a microlaser dissecting tool combined with new gripping systems, recently developed in the robotics field (Saketi et al. 2010; Saketi and Kallio 2011), might allow tensile tests on isolated wood cell walls in "any" direction and by controlled humidity.

The requirement to embed wood samples for nanoindentation is restricted to several types of experiments. The embedding procedure might alter previously performed wood modifications, even if it seems that classical embedding resins do not penetrate significantly into the cell wall, and is mainly restricted to limited 
environmental conditions. Cyclic loading-unloading, which allows the detection of edge effects together with very flat (cryo)ultramicrotomed surfaces, might open the possibility to indent on unembedded, humidity-controlled wood samples. Moreover, precise measurements, which allow the major cell wall elastic properties to be determined, require accurate knowledge of the microfibril orientation with respect to the loading direction. The understanding of hardness values, which are matrix predominant, require more research to understand the basic mechanisms of wood plasticity at the cell wall scale. Finally, nanoindentation is a relevant tool for understanding the impact of wood modification and the origin of changes in the mechanical properties at the macroscopic scale. New techniques (e.g. AFM) may allow one to go down the scale and to measure properties in other layers than the $\mathrm{S}_{2}$-one and/or at the ultrastructural level.

Acknowledgments This review was done within the network of the COST Action FP 0802 "Experimental and computational micro-characterisation techniques in wood mechanics". The authors are thankful for the support coming from the European Science Foundation.

\section{References}

Adusumalli RB, Raghavan R, Ghisleni R, Zimmermann T, Michler J (2010) Deformation and failure mechanism of secondary cell wall in Spruce late wood. Appl Phys A 100(2):447-452

Alméras T, Fournier M (2009) Biomechanical design and long-term stability of trees: morphological and wood traits involved in the balance between weight increase and the gravitropic reaction. $\mathrm{J}$ Theor Biol 256(3):370-381

Archer RR (1986) Growth stresses and strains in trees. In: Timell E (ed) Springer series in wood science. Springer, Berlin, p 240

Barber NF, Meylan BA (1964) The anisotropic shrinkage of wood: a theoretical model. Holzforschung 18:146-156

Barkas WW (1939) Wood water relationships. IV. The swelling and shrinkage of wood in relation to its mechanical properties. Trans Faraday Soc 35(1):0388-0396

Bergander A, Salmén L (2000a) The transverse elastic modulus of the native wood fibre wall. J Pulp Paper Sci 26(6):234-238

Bergander A, Salmén L (2000b) Variations in transverse fibre wall properties: relations between elastic properties and structure. Holzforschung 54:654-660

Bhushan B, Fuchs H (2009) Applied scanning probe methods XI, nano science and technology series. Springer, Berlin

Bonser RHC, Ennos AR (1998) Measurement of prestrain in trees: implication for the determination of safety factors. Funct Ecol 12:1971-1974

Brandt B, Zollfrank C, Franke O, Fromm J, Goken M, Durst K (2010) Micromechanics and ultrastructure of pyrolysed softwood cell walls. Acta Biomater 6(11):4345-4351

Burgert I, Keckes J, Frühmann K, Fratzl P, Tschegg SE (2002) A comparison of two techniques for wood fiber isolation: evaluation by tensile tests of single fibres with different microfibril angle. Plant Biol 4(1):9-12

Burgert I, Frühmann K, Keckes J, Fratzl P, Stanzl-Tschegg SE (2003) Microtensile testing of wood fibers combined with video extensometry for efficient strain detection. Holzforschung 57(6):661-664

Burgert I, Frühmann K, Keckes J, Fratzl P, Stanzl-Tschegg S (2004) Structure-function-relationships of four compression wood types: micromechanical properties at the tissue and fibre level. Trees 18:480-485

Burgert I, Eder M, Frühmann K, Keckes J, Fratzl P, Stanzl-Tschegg S (2005) Properties of chemically and mechanically isolated fibres of spruce (Picea abies [L] Karst.). Part 3: mechanical characterisation. Holzforschung 59:354-357

Burgert I, Eder M, Gierlinger N, Fratzl P (2007) Tensile and compressive stresses in tracheids are induced by swelling based on geometrical constraints of the wood cell. Planta 226:981-987 
Bytebier K, Arnould O, Arinero R (2009) Mechanical characterization of wood viscoelasticity at the submicrometre scale. In: COST FP0802: workshop on experimental and computational methods in wood micromechanics, Vienna, Austria, 11-13 May 2009

Cave ID, Hutt L (1969) The longitudinal Young's modulus of Pinus Radiata. Wood Sci Technol 3(1):40-48

Cheng YT, Cheng CM (2004) Scaling, dimensional analysis, and indentation measurements. Mat Sci Eng B 44(4-5):91-149

Cheng QZ, Wang SQ (2008) A method for testing the elastic modulus of single cellulose fibrils via atomic force microscopy. Comp Part A 39(12):1838-1843

Clair B, Arinero R, Lévêque G, Ramonda M, Thibaut B (2003) Imaging the mechanical properties of wood cell wall layers by atomic force modulation microscopy. IAWA J 24(3):223-230

De Borst K, Bader TK, Wikete C (2012) Microstructure-stiffness relationships of ten European and tropical hardwood species. J Struct Biol 177:532-542

Dinwoodie JM (1975) Timber-a review of the structure-mechanical property relationship. J Microsc 104:3-32

Dong F, Olsson A-M, Salmén L (2010) Fibre morphological effects on mechano-sorptive creep. Wood Sci Technol 44(3):475-783

Doyle J, Walker JCF (1985) Indentation hardness of wood. Wood Fiber Sci 17(3):369-376

Eder M (2007) Structure, properties and function of single wood fibres of Norway spruce (Picea abies [L.] Karst.). Dissertation, BOKU-University of Natural Resources and Applied Life Sciences Vienna

Eder M, Stanzl-Tschegg S, Burgert I (2008a) The fracture behaviour of single wood fibres is governed by geometrical constraints: in situ ESEM studies on three fibre types. Wood Sci Technol 42(8):679-689

Eder M, Terziev N, Daniel G, Burgert I (2008b) The effect of (induced) dislocations on the tensile properties of individual Norway spruce fibres. Holzforschung 62:77-81

Eder M, Jungnikl K, Burgert I (2009) A close-up view of wood structure and properties across a growth ring of Norway spruce (Picea abies [L] Karst.). Trees 23:79-84

Ehrnrooth EM, Kolseth P (1984) The tensile testing of single wood fibers in air and in water. Wood Fiber Sci 16(4):549-566

Eichhorn SJ, Sirichaist J, Young RJ (2001) Deformation mechanisms in cellulose fibres, paper and wood. J Mater Sci 36:3129-3135

Fengel D (1967) Ultramicrotomy, its application in wood research. Wood Sci Technol 1:191-204

Fisher-Cripps AC (2011) Nanoindentation. Springer, New York

Gershon AL, Bruck HA, Xu SW, Sutton MA, Tiwari V (2010) Multiscale mechanical and structural characterizations of Palmetto wood for bio-inspired hierarchically structured polymer composites. Mat Sci Eng C 30(2):235-244

Gierlinger N, Schwanninger M, Reinecke A, Burgert I (2006) Molecular changes during tensile deformation of single wood fibers followed by Raman microscopy. Biomacromolecules 7(7):20772081

Gindl W, Gupta HS (2002) Cell-wall hardness and Young's modulus of melamine-modified spruce wood by nano-indentation. Comp Part A 33(8):1141-1145

Gindl W, Schöberl T (2004) The significance of the elastic modulus of wood cell walls obtained from nanoindentation measurements. Comp Part A 35:1345-1349

Gindl W, Gupta HS, Grunwald C (2002) Lignification of spruce tracheid secondary cell walls related to longitudinal hardness and modulus of elasticity using nano-indentation. Can J Bot 80(10):10291033

Gindl W, Gupta HS, Schöberl T, Lichtenegger HC, Fratzl P (2004) Mechanical properties of spruce wood cell walls by nanoindentation. Appl Phys A 79:2069-2073

Goswami L, Eder M, Gierlinger N, Burgert I (2008) Inducing large deformation in wood cell walls by enzymatic modification. J Mater Sci 43:1286-1291

Griffith AA (1921) The phenomena of rupture and flow in solids. Philos Trans R Soc Lond A 221:163-198

Groom L, Mott L, Shaler S (2002) Mechanical properties of individual southern pine fibers. Part I. Determination and variability of stress-strain curves with respect to tree height and juvenility. Wood Fiber Sci 34(1):14-27

Hartler N, Kull G, Stockman L (1963) Determination of fibre strength through measurement of individual fibres. Svensk Papperstidn 66(8):301-308

Hepworth DG, Vincent JFV, Jeronimidis G, Bruce DM (2000) The penetration of epoxy resin into plant fibre cell walls increases the stiffness of plant fibre composites. Comp Part A 31(6):599-601 
Hinterstoisser B, Akerholm M, Salmén L (2001) Effect of fiber orientation in dynamic FTIR study on native cellulose. Carbohyd Res 334:27-37

Hornatowska J (2009). Fracture mechanisms observed during tensile testing of single fibres. In: COST FP0802: workshop on single fiber testing and modelling, Innventia AB, Stockholm, Sweden, 4-5 Novenber 2009

Jäger A, Bader T, Hofstetter K, Eberhardsteiner J (2011a) The relation between indentation modulus, microfibril angle, and elastic properties of wood cell walls. Comp Part A 42(6):677-685

Jäger A, Hofstetter K, Buksnowitz C, Gindl-Altmutter W, Konnerth J (2011b) Identification of stiffness tensor components of wood cell walls by means of nanoindentation. Comp Part A 42(12):2101-2109

Jakes JE, Frihart CR, Beecher JF, Moon RJ, Stone DS (2008) Experimental method to account for structural compliance in nanoindentation measurements. J Mater Res 23(4):1113-1127

Jakes JE, Frihart CR, Beecher JF, Moon RJ, Resto PJ, Melgarejo ZH, Suarez OM, Baumgart H, Elmustafa AA, Stone DS (2009a) Nanoindentation near the edge. J Mater Res 24(3):1016-1031

Jakes JE, Frihart CR, Stone DS (2009b) Creep properties of micron-size domains in ethylene glycol modified wood across 41/2 decades in strain rate. Mater Res Soc Symp Proc 1132:6

Jayme G, Fengel D (1962) Elektronenoptische Beobachtungen über den Feinbau von Nadel-Holzzellen. Angew Chem Int Ed 74(19):758

Jayne BA (1959) Mechanical properties of wood fibers. Tappi 42(6):461-467

Kallmes OJ, Perez M (1966) Load/elongation properties of fibres. Consolidation of the paper web. Trans Fundam Res Symp F Bolam, Cambridge, B.P. \& B.M.A. 1:507-528

Kamiyama T, Suzuki H, Sugiyama J (2005) Studies of the structural change during deformation in Cryptomeria japonica by time-resolved synchrotron small-angle X-ray scattering. J Struct Biol 151(1):1-11

Kamke FA, Lee JN (2007) Adhesive penetration in wood-a review. Wood Fiber Sci 39(2):205-220

Keckes J, Burgert I, Frühmann K, Müller M, Kölln K, Hamilton M, Burghammer M, Roth SV, StanzlTschegg S, Fratzl P (2003) Cell-wall recovery after irreversible deformation of wood. Nat Mater 2:810-814

Kersevage PC (1973) Moisture content effect on tensile properties of individual Douglas-fir latewood tracheids. Wood Fiber Sci 5(2):105-117

Keunecke D, Eder M, Burgert I, Niemz P (2008) Micromechanical properties of common yew (Taxus baccata) and Norway spruce (Picea abies) transition wood fibers subjected to longitudinal tension. J Wood Sci 54:420-422

Kim CY, Page DH, El-Hosseiny F, Lancaster APS (1975) Mechanical properties of single wood pulp fibers.3. Effect of drying stress on strength. J Appl Polym Sci 19(6):1549-1562

Köhler L, Spatz H-C (2002) Micromechanics of plant tissues beyond the linear-elastic range. Planta 215:33-40

Kollmann F (1951) Technologie des Holzes und der Holzwerkstoffe. Bd. 1. Springer, Berlin

Kolln K, Grotkopp I, Burghammer M, Roth SV, Funari SS, Dommach M, Muller M (2005) Mechanical properties of cellulose fibres and wood. Orientational aspects in situ investigated with synchrotron radiation. J Synchrotron Radiat 12:739-744

Kolseth P (1983) Torsional properties of single wood pulp fibers. Dissertation, The Royal Institute of Technology Stockholm

Kolseth P, Ehrnrooth EML (1986) Mechanical softening of single wood pulp fibers. In: Bristow JA, Kolseth P (eds) Paper structure and properties. Marcel Dekker Inc., New York, pp 27-50

Konnerth J, Harper D, Lee SH, Rials TG, Gindl W (2008) Adhesive penetration of wood cell walls investigated by scanning thermal microscopy (SThM). Holzforschung 62(1):91-98

Konnerth J, Gierlinger N, Keckes J, Gindl W (2009) Actual versus apparent within cell wall variability of nanoindentation results from wood cell walls related to cellulose microfibril angle. J Mater Sci 44(16):4399-4406

Konnerth J, Eiser M, Jäger A, Bader TK, Hofstetter K, Follrich J, Ters T, Hansmann C, Wimmer R (2010) Macro- and micro-mechanical properties of red oak wood (Quercus rubra L.) treated with hemicellulases. Holzforschung 64(4):447-453

Le Rouzic J, Delobelle P, Cretin B, Vairac P, Amiot F (2012) Simultaneous measurement of Young's modulus and Poisson's ratio at microscale with two-modes scanning microdeformation microscopy. Mater Lett 68:370-373

Leopold B, Thorpe JL (1968) Effect of pulping on strength properties of dry and wet pulp fibers from Norway spruce. Tappi 51(7):304-308 
Ljungqvist C-H (2004) Determination of Weibull parameters by single fibre fragmentation for use in modelling of paper tensile properties. Dissertation, Karlstad University

Montero C, Clair B, Alméras T, van der Lee A, Gril J (2012) Relationship between wood elastic strain under bending and cellulose crystal strain. Comp Sci Technol 72:175-181

Mott L, Shaler S, Groom L, Liang B-H (1995) The tensile testing of individual wood fibers using environmental scanning electron microscopy and video imaging analysis. Tappi 78(5):143-148

Mott L, Shaler S, Groom L (1996) A technique to measure strain distributions in single wood pulp fibers. Wood Sci Techol 28(4):429-437

Mott L, Groom L, Shaler S (2002) Mechanical properties of individual southern pine fibers. Part II. Comparison of earlywood and latewood fibers with respect to tree height and juvenility. Wood Fiber Sci 34(2):221-237

Moulia B, Coutand C, Lenne C (2006) Posture control and skeletal mechanical acclimation in terrestrial plants: implications for mechanical modeling of plant architecture. Am J Bot 93(10):1477-1489

Nair SS, Wang SQ, Hurley DC (2010) Nanoscale characterization of natural fibers and their composites using contact-resonance force microscopy. Comp Part A 41(5):624-631

Navi P, Meylan B, Plummer CJG (2006) Role of hydrogen bonding in wood stress relaxation under humidity variation. International conference on integrated approach to wood structure, behavior and application. Joint meeting of ESWM and COST Action E35, Florence, Italy

Neagu RC, Gamstedt EK, Bardage SL, Lindström M (2006) Ultrastructural features affecting mechanical properties of wood fibres. Wood Mater Sci Eng 1:146-170

Niemz P (1993) Physik des Holzes und der Holzwerkstoffe. DRW-Verlang, Leinfelden Echterdingen

Oliver WC, Pharr GM (1992) An improved technique for determining hardness and elastic-modulus using load and displacement sensing indentation experiments. J Mater Res 7(6):1564-1583

Oliver WC, Pharr GM (2004) Measurement of hardness and elastic modulus by instrumented indentation: advances in understanding and refinements to methodology. J Mater Res 19(1):3-20

Oliver WC, Pharr GM (2010) Nanoindentation in materials research: past, present, and future. MRS Bull 35(11):897-907

Olsson A-M, Salmén L, Eder M, Burgert I (2007) Mechano-sorptive creep in wood fibres. Wood Sci Technol 41:59-67

Orso S, Wegst UGK, Arzt E (2006) The elastic modulus of spruce wood cell wall material measured by an in situ bending technique. J Mater Sci 41:5122-5126

Pagano NJ, Halpin JC, Whitney JM (1968) Tension buckling of anisotropic cylinders. J Compos Mater 2:154-167

Page DH, El-Hosseiny F (1976) The mechanical properties of single wood pulp fibers Part 4. The influence of defects. Sven Papperstidn 77(14):71-474

Page DH, El-Hosseiny F (1983) The mechanical properties of single wood pulp fibres. Part VI. Fibril angle and the shape of the stress-strain curve. J Pulp Pap Sci 9(4):99-100

Page DH, El-Hosseiny F, Winkler K (1971) Behaviour of single wood fibres under axial tensile strain. Nature 229:252-253

Page DH, El-Hosseiny F, Winkler K, Bain R (1972) The mechanical properties of single wood-pulp fibres. Part I: a new approach. Pulp Paper Mag Can 73:72-77

Page DH, El-Hosseiny F, Winkler K, Lancaster APS (1977) Elastic modulus of single wood pulp fibers. Tappi 60(4):114-117

Peura M, Muller M, Serimaa R, Vainio U, Saren MP, Saranpaa P, Burghammer M (2005) Structural studies of single wood cell walls by synchrotron X-ray microdiffraction and polarised light microscopy. Nucl Instrum Methods B 238(1-4):16-20

Peura M, Grotkopp I, Lemke H, Vikkula A, Laine J, Muller M, Serimaa R (2006) Negative Poisson ratio of crystalline cellulose in kraft cooked Norway spruce. Biomacromolecules 7(5):1521-1528

Peura M, Kölln K, Grotkopp I, Saranpää P, Müller M, Serimaa R (2007) The effect of axial strain on crystalline cellulose in Norway spruce. Wood Sci Technol 41(7):565-583

Reiterer A, Lichtenegger HC, Stanzl-Tschegg S, Fratzl P (1999) Experimental evidence for a mechanical function of the cellulose microfibril angle in wood cell walls. Philos Mag A 79(9):2173-2184

Saketi P, Kallio P (2011) Measuring bond strengths of individual paper fibers using microrobotics. In: Progress in paper physics seminar, Graz, Austria, Verlag der Technischen Universität Graz, pp 199-203

Saketi P, Treimanis A, Fardim P, Ronkanen P, Kallio P (2010) Microrobotic platform for manipulation and flexibility measurement of individual paper fibers. In: IEEE/RSJ international conference on intelligent robots and systems (IROS), Taipei, China, 18-22 October 2010, pp 5762-5767 
Salmén L (2004) Micromechanical understanding of the cell-wall structure. CR Biol 327:873-880

Salmén L, de Ruvo A (1985) A model for the prediction of fiber elasticity. Wood Fiber Sci 17(3):336-350

Scurfield G (1973) Reaction wood: its structure and function. Science 179(4074):647-655

Sedighi-Gilani M, Navi P (2006) Experimental observations and micromechanical modeling of successive-damaging phenomenon in wood cells' tensile behavior. Wood Sci Technol 41(1):69-85

Sedighi-Gilani M, Sunderland H, Navi P (2005) Microfibril angle non-uniformities within normal and compression wood tracheids. Wood Sci Technol 39(6):419-430

Sedighi-Gilani M, Sunderland H, Navi P (2006) Within-fiber nonuniformities of microfibril angle. Wood Fiber Sci 28(1):132-138

Seisto A, Poppius-Levlin K, Fuhrmann A (1998) Correlation between chemical, fibre and paper properties of peracid- and chlorine dioxide-bleached pine and birch kraft pulps by multivariate analysis. Pap Puu-Pap Tim 80(7):520-528

Speck T, Rowe NP, Spatz HC (1996) Pflanzliche Achsen, hochkomplexe Verbundmaterialien mit erstaunlichen mechanischen Eigenschaften. BIONA-report 10-Technische Biologie und Bionik 3, Akad Wiss u Lit Mainz W Nachtigall and A Wisser. Fischer Verlag, Stuttgart, pp 101-131

Stanzl-Tschegg S, Beikircher W, Loidl D (2009) Comparison of mechanical properties of thermally modified wood at growth ring and cell wall level by means of instrumented indentation tests. Holzforschung 63(4):443-448

Tabor D (1951) The hardness and strength of metals. J Inst Met 79(7):1-18

Tabor D (1996) Indentation hardness: fifty years on a personal view. Philos Mag A 74(5):1207-1212

Thygesen LG, Eder M, Burgert I (2007) Dislocations in single hemp fibres-investigations into the relationship of structural distortions and tensile properties at the cell wall level. J Mater Sci 42:558-564

Tomasetti E, Legras R, Nysten B (1998) Quantitative approach towards the measurement of polypropylene/(ethylene-propylene) copolymer blends surface elastic properties by AFM. Nanotechnology 9(4):305-315

Tze WTY, Wang S, Rials TG, Pharr GM, Kelley SS (2007) Nanoindentation of wood cell walls: continuous stiffness and hardness measurements. Comp Part A 38:945-953

Vlassak JJ, Ciavarella M, Barber JR, Wang X (2003) The indentation modulus of elastically anisotropic materials for indenters of arbitrary shape. J Mech Phys Solids 51(9):1701-1721

Wang G, Yu Y, Shi SQ, Wang JW, Cao SP, Cheng HT (2011) Microtension test method for measuring tensile properties of individual cellulosic fibers. Wood Fiber Sci 43(3):251-261

Wardrop $\mathrm{AB}$ (1965) The formation and function of reaction wood. In: Coté WA Jr (ed) Cellular ultrastructure of woody plants. Syracuse University Press, New York, pp 371-390

Wild PM, Provan JW, Guin R, Pop S (1999) The effects of cyclic axial loading of single wood pulp fibers at elevated temperature and humidity. Tappi 82(4):209-215

Wimmer R, Lucas BN (1997) Comparing mechanical properties of secondary wall and cell corner middle lamella in spruce wood. IAWA J 18(1):77-88

Wimmer R, Lucas BN, Tsui TY, Oliver WC (1997) Longitudinal hardness and Young's modulus of spruce tracheid secondary walls using nanoindentation technique. Wood Sci Technol 31(2):31-141

Wu Y, Wang SQ, Zhou DG, Xing C, Zhang Y (2009) Use of nanoindentation and Silviscan to determine the mechanical properties of 10 hardwood species. Wood Fiber Sci 41(1):64-73

Xing C, Wang SQ, Pharr GM, Groom LH (2008) Effect off thermo-mechanical reffering pressure on the properties of wood fibers as measured by nanoindentation and atomic force microscopy. Holzforschung 62(2):230-236

Yamamoto H, Yoshida M, Okuyama T (2002) Growth stress controls negative gravitropism in woody plant stems. Planta 216:280-292

Yin YF, Berglund L, Salmen L (2011) Effect of steam treatment on the properties of wood cell walls. Biomacromolecules 12(1):194-202

Yu Y, Fei BH, Wang HK, Tian GL (2011a) Longitudinal mechanical properties of cell wall of Masson pine (Pinus massoniana Lamb) as related to moisture content: a nanoindentation study. Holzforschung 65(1):121-126

Yu Y, Jiang ZH, Fei BH, Wang G, Wang HK (2011b) An improved microtensile technique for mechanical characterization of short plant fibers: a case study on bamboo fibers. J Mater Sci 46(3):739-746

Zabler S, Paris O, Burgert I, Fratzl P (2010) Moisture changes in the plant cell wall force cellulose crystallites to deform. J Struct Biol 171(2):133-141 
Zhang XN, Zhao QH, Wang SQ, Trejo R, Lara-Curzio E, Du GB (2010) Characterizing strength and fracture of wood cell wall through uniaxial micro-compression test. Comp Part A 41(5):632-638

Zickler GA, Schoberl T, Paris O (2006) Mechanical properties of pyrolysed wood: a nanoindentation study. Philos Mag 86(10):1373-1386

Zimmermann T, Thommen V, Reimann P, Hug HJ (2006) Ultrastructural appearance of embedded and polished wood cell walls as revealed by Atomic Force Microscopy. J Struct Biol 156(2):363-369 